\title{
MEASUREMENT OF THE DETERIORATION OF THE DIESEL ENGINE OIL USING THE IDT CAPACITOR SENSOR
}

\author{
Youn Joung Cho ${ }^{1}$, Tae Ho Sin ${ }^{1}$, Jae Hyeon Jeon ${ }^{1}$, Sang Hoon Lee ${ }^{1 凶}$ \\ ${ }^{1}$ Department of Mechanical and Automotive Engineering, Seoultech, Seoul, Republic of Korea.
}

Received 6 December2021

Accepted 17 December2021

Published 30 January 2022

CorrespondingAuthor

Sang Hoon Lee,

hyla@seoultech.ac.kr

DOI

10.29121/granthaalayah.v10.i1.2022 .4449

Funding: This research received no specific grant from any funding agency in the public, commercial, or not-for-profit sectors.

Copyright: (C) 2022 The Author(s). This is an open access article distributed under the terms of the Creative Commons Attribution License, which permits unrestricted use, distribution, and reproduction in any medium, provided the original author and source are credited.

\section{ABSTRACT}

A capacitor-type engine oil sensor is designed and fabricated to measure the property of the diesel engine oil depending on the vehicle mileage. This sensor has flat structure with the interdigitated (IDT) electrodes for the smooth oil flow and is constructed using printed circuit board (PCB) for the fabrication convenience. For the increased capacitance, the smaller spacing between the electrodes is preferred and determined with $0.5 \mathrm{~mm}$ based on the fabrication limit. The device is applied to actual trucks with diesel engine. From the experiment, the capacitance of vehicle $A$ is initially constant and then increased upto approximately $6,000 \mathrm{~km}$. And then, the output is dramatically decreased, which indicates that the engine oil has been degraded and should be replaced. The interval at which the reduction in capacitance occurs varies depending on each vehicle, which means the exchange interval of engine oil is different from each other. The degree of deterioration of the oil is also measured with the viscosity tests and total acid number (TAN) tests, and the results are compatible with the measurement of capacitance. From these results, it has been confirmed that the fabricated IDT capacitor sensor can measure the engine oil conditions depending on the mileage.

Keywords: Engine Oil, Capacitance, Dielectric Constant, Oil Deterioration, Interdigitated (IDT) Capacitor Sensor

\section{INTRODUCTION}

The engine oil forms a thin oil film inside the engine, minimizes abrasion and friction between metals, and serves to keep the engine clean and cool Kim et al. (2017), Raposo et al. (2019). Since the engine oil is an additive and makes the engine run smoothly, it should be changed in the proper time. If the engine oil exchange is delayed, the viscosity may be increased due to the depletion of the oil liquidization agent or be reduced by changes in the components caused by metal debris and shear forces caused by continued engine running. For this reason, a change in the viscosity of the engine oil can significantly reduce the efficiency and performance of the engine, which can damage the vehicle Guan et al. (2011), Akbiyik et al. (2022), Agoston et al. (2005).

On the other hand, frequent replacing of engine oil causes social problems such as economic loss, waste of resources, and environmental pollution caused by the generation of large amount of waste oil Agoston et al. (2005). Therefore, changing the engine oil at the correct time is very important.

According to the instruction manual of automakers, the proper exchange of engine oil is around 10,000 to 20,000 kilometers, and also recommended to be changed every 12 months Kim et al. (2014). However, because the timing 
of the change of engine oil depends on the characteristics of the driver, driving environment, and mileage, drivers need to change the engine oil according to their individual driving characteristics. Therefore, it is necessary to detect the status of engine oil in order to check the appropriate exchange cycle. From early 2000s, various research has been performed with the viscosity Agoston et al. (2005), Yanaseko et al. (2019), dielectric constant Dingxin et al. (2011), Kim et al. (2014), and TAN of engine oil Kim et al. (2001) for the proper exchange time.

In this study, an interdigitated (IDT) capacitor sensor was developed that can detect the condition of the oil by using the capacitance value to determine the characteristics of the engine oil. The designed sensors were simply fabricated using a lithography process with a PCB board, and they measured the capacitance value of the engine oil. Prior to actual vehicle application, preliminary experiments were conducted in the laboratory to determine the basic characteristics of the sensors, and to check the temperature effect on the engine oil. Based on these results, we applied the sensors to the engine oil collected from actual transported vehicles and performed the experiments to measure the degradation state with the capacitance change.

\section{THEORETICAL BACKGROUND \\ 2.1. PRINCIPLE OF SENSOR MEASUREMENT}

There are many ways to measure the degradation of engine oil. First, there is a method using viscosity. The viscosity changes due to the change of additives and oil composition during operation. This value can be used to determine the degradation of the engine oil. Another way is to measure the total amount of acid (TAN) in the engine oil. The oil (hydrocarbons) reacts with the oxygen and is gradually oxidized during the operation. Oxidization reduces the performance of engine oil, and the degree of oxidation can be measured with TAN value. The TAN value is represented with the amount of Potassium hydroxide ( $\mathrm{KOH}$ in $\mathrm{mg}$ ) to neutralize the acid. However, the measurements with viscosity and TAN requires the expensive equipment or long-term verification. To solve these problems, we used a capacitive measurement method. The capacitance is the value of accumulated charge when the voltage is applied to the separated conductors. The capacitance is related with the permittivity of engine oil and can be simply measured without additional equipments. Moreover, the capacitor can be easily fabricated with standard lithography process.

The various types of capacitors have been used like a co-axis circular capacitor, a parallel plate capacitor, and IDT capacitor with multiple finger electrodes. In this study, the IDT capacitor form was adopted because the spacing between electrodes can be precisely defined with the conventional fabrication process, and the engine oil can pass over the capacitor with less resistance. Figure 1 shows the schematic view of the designed sensor with the IDT capacitor. In the IDT capacitor, the total capacitance is known as equation (1) and (2) Liu et al. (2015), 

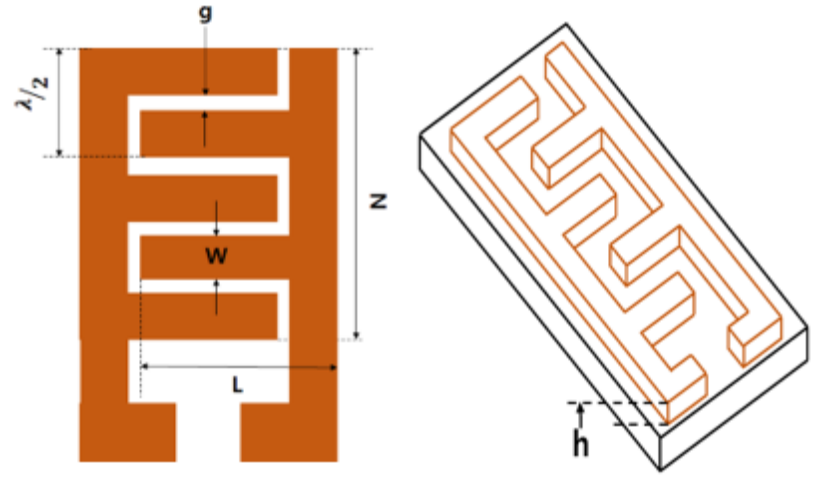

Figure 1 Schematic view of the designed IDT capacitor sensor

$$
\begin{aligned}
& C=\varepsilon_{0}\left[f(\lambda, g)+\varepsilon_{s} \frac{h}{g}\right] \times(N-1) \times L \\
& f(\lambda, g)=\frac{\varepsilon_{m}+\varepsilon_{s}}{2} \frac{K\left[\sqrt{1-(2 g / \lambda)^{2}}\right]}{K[2 g / \lambda]}
\end{aligned}
$$

where $C, \varepsilon_{0}, \varepsilon_{\mathrm{m}}$, and $\varepsilon_{\mathrm{s}}$ represents the capacitance of engine oil, dielectric constant of air, relative dielectric constants of oil and substrate, respectively. The dimensions of IDT capacitor are also considered in equation (1) and (2) using the length (L), height (h), and spacing of fingers (g). The width (W) is used in the form of wavelength $(\lambda)$. The number of fingers, $N$ are also involved.

For the device design, the analysis was carried out to identify the overall trend of the variables. The equation (1) and (2) have the primary elliptical integration, and we use the commercial engineering tool, MATLAB. As shown in Figure 2, the function $\mathrm{f}$ in equation (1) increases as the spacing between the fingers decreases. Since the equation (1) is proportional to equation (2), reducing the spacing between fingers increases the capacitance value. It is also shown that increasing $\mathrm{N}$ and $\mathrm{L}$ values through equation (1) results in a large capacitance value as shown in Figure 3. Therefore, the size of the sensor should be as large as possible, and the spacing between the fingers should be minimized in order to increase the capacitance value for the stability of the sensor.

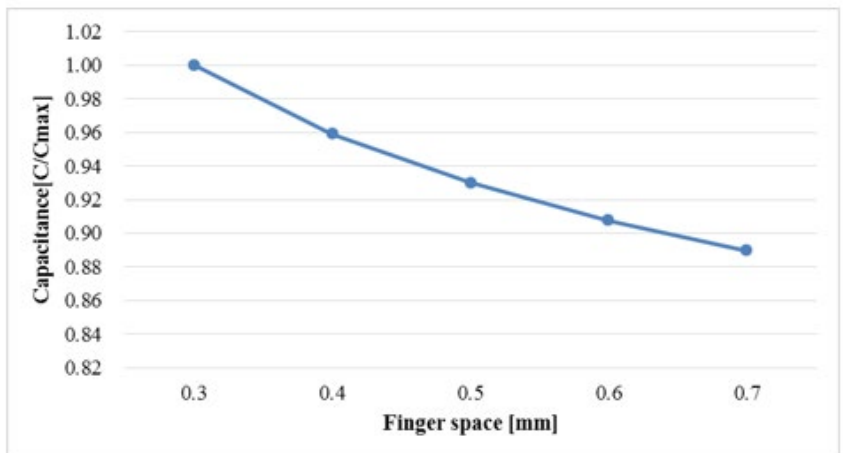

Figure 2 The capacitance graph in IDT sensor with finger spacing 


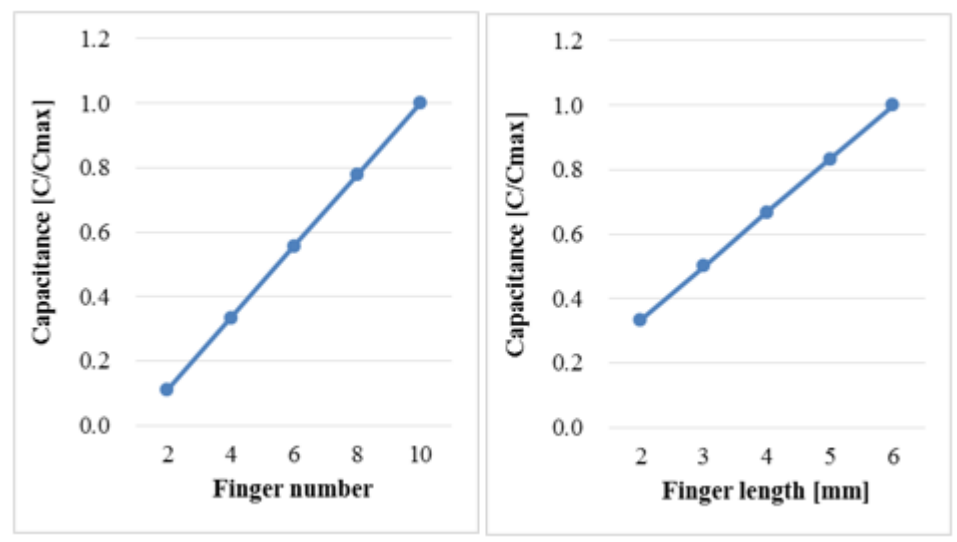

Figure 3 The capacitance graph with finger number (left) and finger length (right)

\subsection{PRELIMINARY INVESTIGATION ON DIESEL ENGINE OIL}

The moisture can be contained in the engine oil during the engine operation. In that case, the composition of engine oil is changed, and the accurate measurement of the capacitive change can be interfered Qiang et al. (2012). Therefore, the temperature should be increased by more than $80^{\circ} \mathrm{C}$ for the less influence of the moisture. And the temperature of the engine oil in the vehicle is maintained between 80 and $95^{\circ} \mathrm{C}$ by the cooling system of the vehicle Kim et al. (2017). As the engine oil may have different characteristics depending on temperature, the temperature of the engine oil needs to be specified based on that of actual vehicle. Therefore, prior to the experiments of engine oil taken from the actual vehicle, the test should be conducted to determine the characteristics of the engine oil according to the temperature. The experiment was performed using the new oil and the capacitance change was measured every $10{ }^{\circ} \mathrm{C}$ from $40{ }^{\circ} \mathrm{C}$ to $80^{\circ} \mathrm{C}$. As shown in Figure 4 , it can be seen that the capacitance value increases proportionally with the temperature and represents a certain range of capacitance values for each temperature.

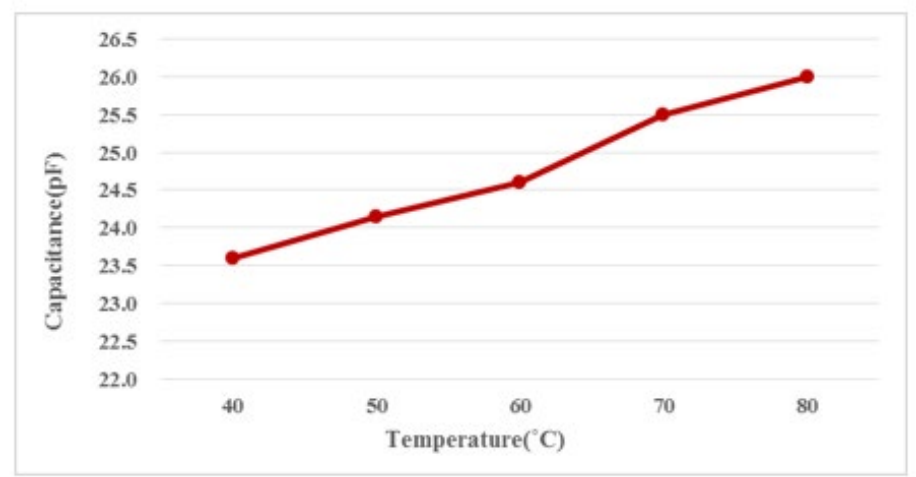

Figure 4 Capacitance measurement results with respect to temperature

From these results, the temperature should be remained constant in the experiments, since the value of the capacitance of the engine oil changes with the temperature. In this study, all experiments were conducted by setting the temperature of $80^{\circ} \mathrm{C}$, which was in the temperature range of the actual operating engine. 


\section{EXPERIMENTAL SETUP}

\subsection{FABRICATION OF IDT CAPACITOR SENSOR}

Like Figure 5, an IDT capacitor sensor was manufactured to measure the capacitive change of the engine oil to determine the deterioration characteristics. It was made from PCB substrate through the lithography and etching processes.

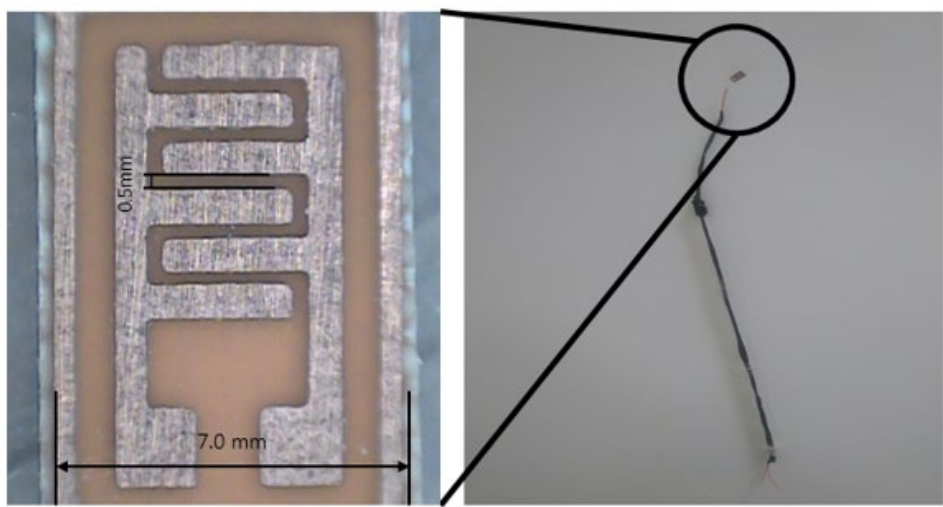

(a) IDT capacitor

(b) Engine oil sensor assembly

Figure 5 The photos of fabricated IDT capacitor sensor and assembly

According to the electrostatic capacitance formula (1), the smaller the spacing between electrode fingers, the higher capacitance value can be achieved. The various spacing were designed as $0.4 \mathrm{~mm}, 0.5 \mathrm{~mm}, 0.6 \mathrm{~mm}$ and $0.7 \mathrm{~mm}$. However, in the case of $0.4 \mathrm{~mm}$ intervals, the sensor pattern was not clearly patterned as shown in Figure 6 due to the the limitation of the PCB fabrication system. In comparison, the sensors with over $0.5 \mathrm{~mm}$ gap were fabricated with the correct dimensions. Based on these results, the spacing between electrodes of the IDT capacitor sensors was selected as the manufacturing limit of $0.5 \mathrm{~mm}$. If the improved lighography system like commercial MEMS fabrication system is applied, the spacing can be reduced to the micrometer scale. The length and number of fingers were also to be maximized for the increased capacitance. The minimum inner diameter of the dipstick tube was $8 \mathrm{~mm}$, and the width of sensor was limited as $7 \mathrm{~mm}$ for the actual vehicle application. According to those dimensions, the number of fingers were set to be 6 sets. And, after the wire connections, the lower part of the sensor was fixed to prevent the wire movement using a plastic tube.

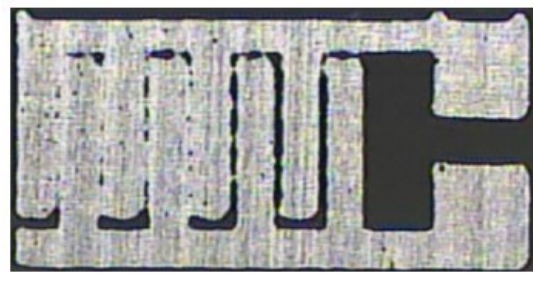

(a) $0.4 \mathrm{~mm}$ spacing case

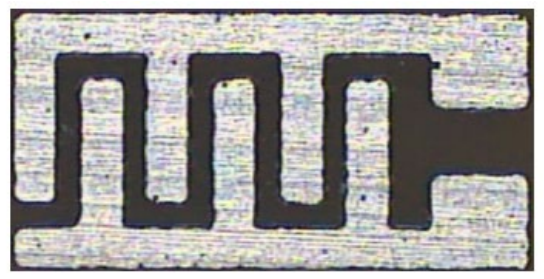

(b) $0.5 \mathrm{~mm}$ spacing case

Figure 6 Fabricated devices with different electrode spacing 


\subsection{EXPERIMENTAL METHOD WIH IDT CAPACITOR SENSOR}

In this study, the engine oil in the actual vehicle was used, which are around six liter. For the measurement, some amount of oil was extracted, and the fresh oil was replenished to maintain the constant volume. However, the added oil may change the characteristics of measured engine oil. Therefore, considering the 10 times extractions, the total adding amount of engine oil should not be exceed some portion of the engine oil. As a results, $80 \mathrm{ml}$ of oil was extracted and supplemented so that even 10 times does not exceed one sixth of the total oil volume. The engine oil was extracted every $900 \mathrm{~km}$, which was carried out up to 10,000 km.

The experimental setting is shown in Figure 7. During the experiments, the temperature of the engine oil is kept at $80{ }^{\circ} \mathrm{C}$ through the heater. To check the condition of the engine oil, the capacitance value was measured using an Arduino circuit.

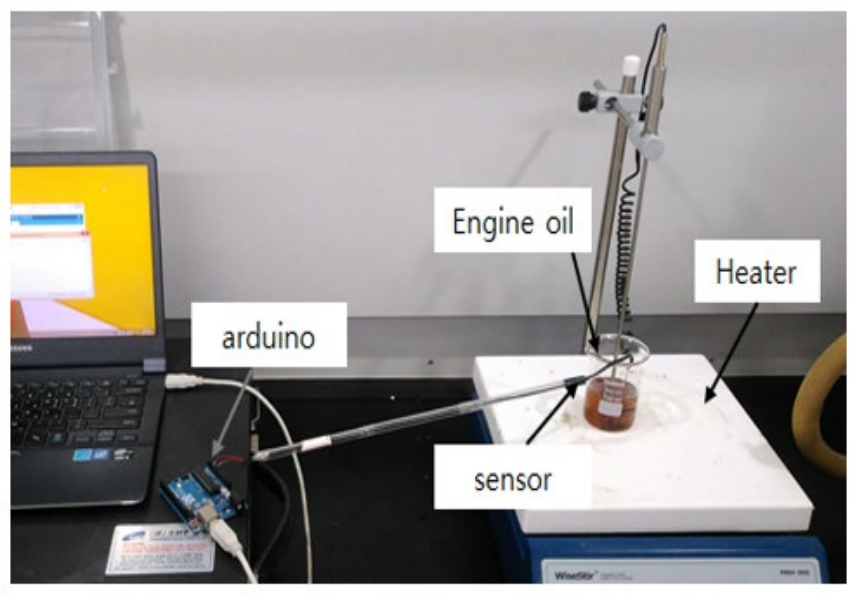

Figure 7 Experimental setup for measurement of engine oil deterioration

The principle of measuring the capacitance value through the Arduino circuit is as shown in Figure 8. There are several ways to measure the capacitance, and here, the time constant (TC) expression was used as shown in equation (3). When voltage is applied and removed on capacitor connected to resistance, the voltage decreases smoothly. The TC means the time that the voltage reaches $63.2 \%$ of the initial value. The fabricated sensor acts as the capacitor, and the TC can be measured with the pull-up resistor in the Arduino circuit.

$$
T C=R \times C
$$

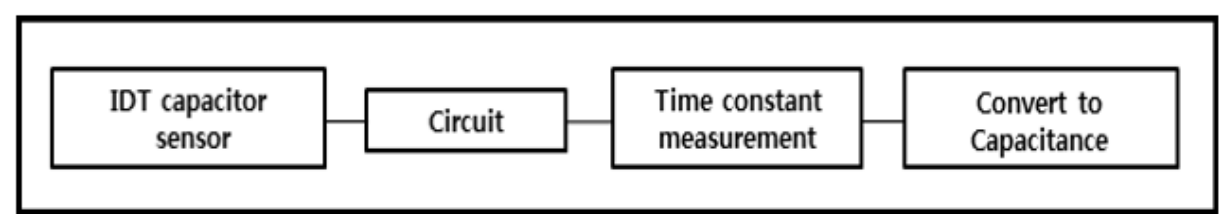

Figure 8 Block diagram of capacitance measurement 


\subsection{EXTRACTION OF DIESEL ENGINE OIL}

The experiments have been performed with three one-ton trucks. One truck drove through the city, while the rest of the test vehicles mainly operated on highways. The measurement cycle was performed at an average of $900 \mathrm{~km}$. As mentioned earlier, the minimum amount, $80 \mathrm{ml}$, was extracted and replenished, that was assumed to have no significant impact taking into account the oil volume of $6 \mathrm{~L}$.

\section{RESULTS AND DISCUSSIONS}

\subsection{MEASUREMENT RESULTS WITH IDC CAPACITOR SENSOR}

The graphs on Figure 9 shows the measurement results of three one-ton trucks. In the case of three subject vehicles, the degradation of the engine oil causes the capacitance to rise and decrease rapidly, depending on the vehicle's mileage.

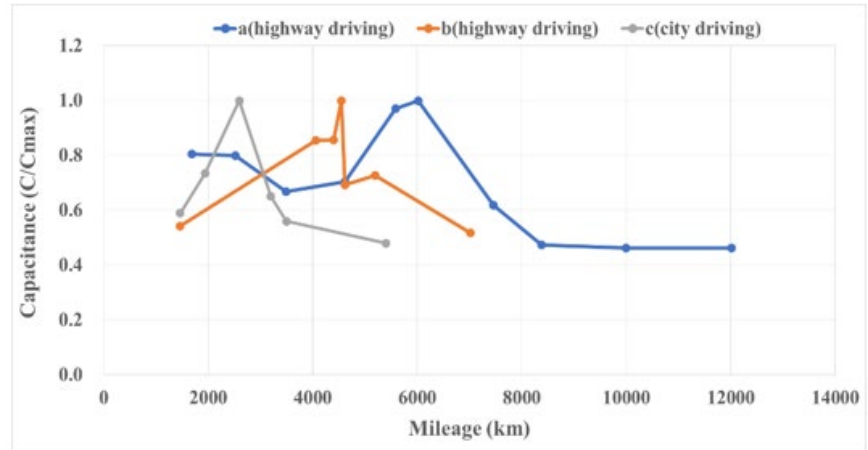

Figure 9 The capacitance measurement results with respect to vehicle mileage

The deterioration of the engine oil can be divided into two main steps Chun (2006). In case of stage 1 , the oil itself is oxidized. The oxidation is initially inhibited by the effects of additives such as antioxidants. However, oxides continue to occur after the exhaustion of antioxidants, resulting the increase of capacitance Cho and Park (2010). In the step 2, the oxidizing speed is reduced due to the concentration of oxides and limited contact with oxygen in the oil. This leads to a reduction in the capacitance, which means the complete deterioration of the engine oil. This is similar to the previous result 1 and can be found to be the end of the life of the engine oil. This indicates that vehicle a has reached the end of life of the engine oil after approximately $6,000 \mathrm{~km}$, vehicle b after about $2,600 \mathrm{~km}$, and vehicle $\mathrm{c}$ after about $4,200 \mathrm{~km}$. Although the used vehicles were of the same type, each time of oil deterioration was different. Therefore, it was apparent that the timing of the engine oil exchange was different for each vehicle.

In the case of vehicle, A in Figure 9, there was a slight decrease in the capacitance at the beginning of the operation. This may temporarily decrease if the antioxidants contained in the engine oil are activated, even in the first stage described earlier Chun (2006). However, as a whole, after a temporary decrease, the capacitance value is increased and then rapidly decreased due to deterioration of the engine oil, which is consistent with the previous oil life characteristics. 


\subsection{MEASUREMENT RESULTS OF VISCOSITY}

To verify the reliability of the capacitance measurement, the viscosity is measured using the engine oil sample of vehicle a. It is carried out with the Brookfield viscometer (DV-III Ultra, Brookfield AMETEK Inc.) like Figure 10. The viscometer measures viscosity using the the torque required to turn the cylinder in the oil. The temperature is maintained with heater and the overall operation is computer controlled.

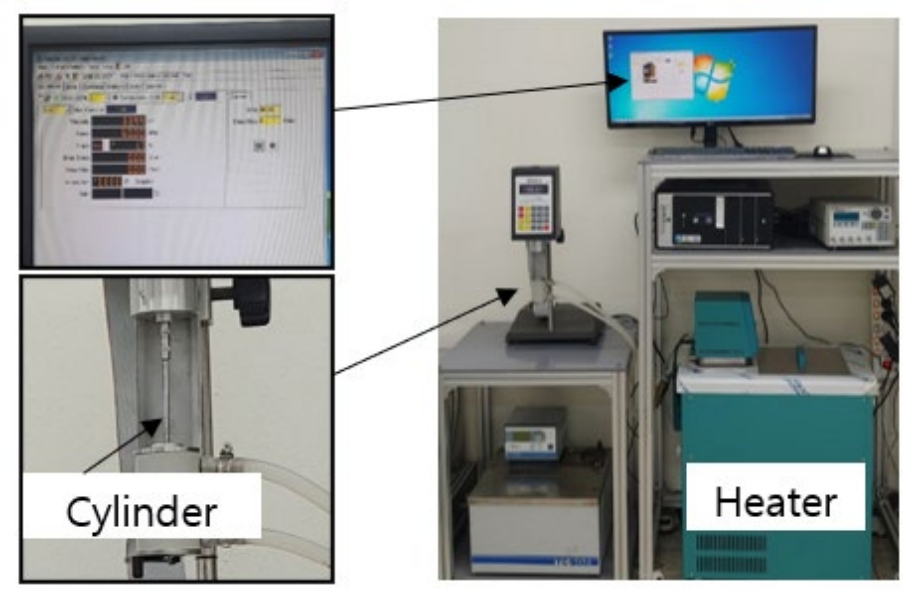

Figure 10 Viscosity measurement system

During the operation, the viscosity of engine oil can be increased or decreased. Generally, the degradation point is known as the time when the viscosity increases over $20 \%$ or decreases less than $15 \%$ compared with that of fresh oil (Hanyu Energy Co., http://www.hanyuenergy.co.kr/kr/techniquelactual_1.asp? ptype=4).

As shown in Table 1, as the operation mileage increases, the viscosity value of engine oil gradually decreases. At the $5,586 \mathrm{~km}$ operation, the viscosity decreases about $11.6 \%$ from $6.72 \mathrm{cp}$ of new oil to $5.94 \mathrm{cp}$. The viscosity value becomes 5.47 $\mathrm{cp}$, which means around $18.6 \%$ variation at $7,463 \mathrm{~km}$ operation. Considering that the deterioration criteria in viscosity is $15 \%$ reduction, we can know that it is located in between $5,586 \mathrm{~km}$ and 7,463 km. This result corresponds to the result of around 6,000 km from the measurement test of capacitance.

\begin{tabular}{|cccc|}
\hline Table 1 & Measurement results on viscosity of engine oil \\
\hline Unit & \multicolumn{4}{c}{ Viscosity measruement result } \\
\hline & New oil & $5,586(\mathrm{~km})$ & $7,463(\mathrm{~km})$ \\
$\mathrm{cp}$ & 6.72 & 5.94 & 5.47 \\
\hline
\end{tabular}

\subsection{MEASUREMENT RESULTS OF TAN VALUE}

To compare the results of vehicle a, the TAN value of engine oil is measured. The testing method was carried out by the Korea Testing Certification (KTC), and the testing method was conducted using KS M ISO 6618: 2003. Generally, if the TAN value of diesel engine oil reaches around $2.0 \mathrm{mg} \mathrm{KOH} / \mathrm{g}$ variation, the oil is considered to become the deterioration state Kim et al. (2017). According to the measurements, the TAN value increased by $0.96 \mathrm{mg} \mathrm{KOH} / \mathrm{g}$ from $1.56 \mathrm{mg} \mathrm{KOH} / \mathrm{g}$ at new oil to $2.52 \mathrm{mg} \mathrm{KOH} / \mathrm{g}$ at 3,493 $\mathrm{km}$. The TAN value reaches $3.38 \mathrm{mg} \mathrm{KOH} / \mathrm{g}$ at 6,017 km with $1.82 \mathrm{mg} \mathrm{KOH} / \mathrm{g}$ increment. Although it is not up to the $2.0 \mathrm{mg} \mathrm{KOH} / \mathrm{g}$ 
value as the deterioration criteria, the close value is obtained, and it can be inferred that the exchange period has reached. In conclusion, the measurement results with TAN value were found to be in the range of about $6,000 \mathrm{~km}$ and the same as the results of measurement of the capacitance and viscosity.

\section{CONCLUSIONS AND RECOMMENDATIONS}

In this study, we designed and fabricated the IDT capacitor sensor, and measured the degradation characteristics of a diesel engine oil. The results are summarized as follows.

1) In this study, an IDT capacitor-type diesel engine oil sensor, which can be mounted on an engine oil level gauge, was developed using PCB board. The sensor measures the deterioration characteristics by measuring the change in the capacitance of the engine oil.

2) Since the capacitance of engine oil increases with temperature, it is necessary to specify the measured temperature. The experiments about temperature effects were performed, and $80^{\circ} \mathrm{C}$ was adapted to measure the characteristics of engine oil, considering actual operation conditions.

3) After comparing the capacitance values of three subject vehicles according to the distance travelled, the time of deterioration of the engine oil was $6,000 \mathrm{~km}$ for vehicle A, 4,400 $\mathrm{km}$ for vehicle b, and 2,600 km for vehicle c. Therefore, the point of deterioration becomes different according to the vehicle types and driver-specific factors.

4) The viscosity of the engine oil for a vehicle was $6.72 \mathrm{cp}$ for $0 \mathrm{~km}$ but decreased to $5.94 \mathrm{cp}$ at 5,586 $\mathrm{km}$ and finally reached to $5.47 \mathrm{cp}$ at 7,463 km. The $15 \%$ reduction point is approximately $6,000 \mathrm{~km}$, and the viscosity result is consistent with the measurement of the capacitance.

5) In case of TAN vale, it has increased by $1.82 \mathrm{mg} \mathrm{KOH} / \mathrm{g}$ at 6,017 km compared to the new oil. This value has almost reached the point of degradation at about $6,000 \mathrm{~km}$. Consequently, it can be seen that the results are similar to those of capacitance measurement.

6) To prevent damage to the sensors caused by vibration and impact of the vehicle, research on the sensor attachment method and the sensor material should be conducted to ensure durability.

\section{REFERENCES}

Agoston, A., Otsch, C., and Jakoby, B., (2005) Viscosity sensors for engine oil condition monitoring-Application and interpretation of results, Sensors and Actuators A : Physical, 121, 327-332. Retrieved from https://doi.org/10.1016/j.sna.2005.02.024

Akbiyik, T., Kahraman, N., Taner, T., (2022) Investigation of the effect of boron additive to lubricating oil on engine performance, exhaust, and emissions, Fuel, 312, 122931 Retrieved from https://doi.org/10.1016/j.fuel.2021.122931

Cho, J., and Park, S., (2010) Capacitive sensor for automotive engine oil degradation using wireless network, 2010 International Symposium on Advanced Packaging Materials : Microtech (APM), Cambridge, USA, 88-91. Retrieved from https://ieeexplore.ieee.org/abstract/document/5441375

Chun, S. M., (2006) Study on Mutual Relation between the Level of Deterioration Influenced by the Changes of Chemical and Physical Properties and the 
change of Dielectric Constant for Engine Oil - diesel Engine Oil, The Korean Society of Tribologists \& Lubication Engineers, 22(5), 290-300. Retrieved from

https://www.koreascience.or.kr/article/JAK0200604623618467.page

Dingxin, Y., Zheng, H. and Jianwei, X., (2011) Research on capacitive sensor for online oil monitoring, 2011 Prognostics and System Health Managment Confernece, Shenzhen, 1-4. Retrieved from https://ieeexplore.ieee.org/abstract/document/5939536

Guan, L., Feng, L. X., Xiong, G., and Xie, J. A., (2011) Application of dielectric spectroscopy for engine lubricating oil degradation monitoring, Sensors and Actuators A : Physical, 168, 22-29. Retrieved from https://doi.org/10.1016/j.sna.2011.03.033

Hanyu

Energy

http://www.hanyuenergy.co.kr/kr/technique/actual_1.asp?ptype=4

Co.,

Kim, M. J., Lee, W. S., and Lee, S. H., (2014) Study on Electric and Magnetic Characteristics of Engine Oil in Transport Truck, The Transactions of the Korean Society of Automotive Engineers, 22(3), 166- 170. Retrieved from https://doi.org/10.7467/KSAE.2014.22.3.166

Kim, M. J., Sin, T. H. and Lee, S. H., (2017) Measurement of the Engine Oil Deterioration of the Diesel Vehicle Using the Engine Oil Level Gauge, The Transactions of the Korean Society of Automotive Engineers, 25(1), 60- 65. Retrieved from https://doi.org/10.7467/KSAE.2017.25.1.060

Kim, Y. D., Chung, K. W and Kang, S. C, (2001) The Study on Field Test of the New Formulated and Commercial Diesel Engine Oils, Transaction of the Korean Society of Automotive Engineers, 9(3), 51-59.

Liu, Y., Huang, Y., Tang, R., and Wang, B., (2015) Application of Interdigital Capacitive sensors for Detecting Power Cable Insulation Damage, proceedings of 2015 IEEE, International Conference on Mechatronics and Automation (ICMA), August 2-5, Beijing, China, 1795-1799. Retrieved from https://doi.org/10.1109/ICMA.2015.7237758

Qiang, L., Jiang, W., Lili, C., and Xiaowei, L. (2012) A Study of Moisture Content of Lubricating Oil Based on Impedance Analysis, Proceedings of 2012 International Conference on Mechanical Engineering and Material Science, 406-409. Retrieved from https://doi.org/10.2991/mems.2012.50

Raposo, H., José T. F., Inácio F., and Ferreira, L. A., (2019) Condition Monitoring with Prediction Based on Diesel Engine Oil Analysis : A Case Study for Urban Buses, Actuators, 8(1), 14-27. Retrieved from https://doi.org/10.3390/act8010014

Yanaseko, T., Sato, H., Kuboki, I., Mossi, K., \& Asanuma, H., (2019) Vibration Viscosity Sensor for Engine Oil Monitoring Using Metal Matrix Piezoelectric Composite. Materials (Basel, Switzerland), 12(20), 3415. Retrieved from https://doi.org/10.3390/ma12203415 